\title{
Undergraduate Students' Perceptions of the Role of the Nurse Educator during Clinical Placements in Malawian
}

\author{
Gladys Msiska, Tiwonge Mbeya Munkhondya, Evelyn Chilemba \\ Kamuzu College of Nursing, University of Malawi, Lilongwe, Malawi \\ Email: gladysmsiska@kcn.unima.mw, tiwongembeya@kcn.unima.mw, evelynchilemba@kcn.unima.mw
}

Received 26 September 2014; revised 25 October 2014; accepted 12 November 2014

Academic Editor: Daniel Fernandez, University of Leon, Spain

Copyright (C) 2014 by authors and Scientific Research Publishing Inc.

This work is licensed under the Creative Commons Attribution International License (CC BY).

http://creativecommons.org/licenses/by/4.0/

(c) (i) Open Access

\begin{abstract}
In this article we reported selected findings of a hermeneutic phenomenological study which explored the clinical learning experience of undergraduate nursing students in Malawi. The setting for the study was a university nursing college and the sample was selected purposively, consisting of thirty participants. Conversational interviews were conducted and a framework developed by modifying Colaizzi's procedural steps guided the phenomenological analysis. The study findings reflect students' perspectives on what the ideal role of a nurse educator in Malawi should entail. Contrary to most of the literature from western countries, the findings strongly indicate the need for nurse educators to teach students during clinical placements by engaging in hands-on-care. Additionally, the study also indicates the need for educators to view their role holistically by focusing on both academic and personal aspects of the students' life. The study illustrates the need for connected educator-student relationships.
\end{abstract}

\section{Keywords}

Student Nurse, Nurse Educator, Phenomenological

\section{Introduction}

The role of the nurse educator has been an area of much debate, more specifically in the United States and the United Kingdom (UK). In the UK, what leads to these debates is the transfer of nurse education into Higher Education Institutions [1]. Though such debates and discussions have tended to focus on the role of nurse edu- 
cators in western countries, the issues are relevant to any country where nursing education is offered within tertiary education. In the UK the transfer of nursing education to institutions of higher learning leads to concerns about the adequacy of clinical nursing education [2]. This became a concern because with nursing being offered within tertiary education, students would have reduced time for practice as opposed to the amount of time that was allotted for clinical practice during the traditional apprenticeship model of nursing education. These concerns led to a recommendation that nurse educators should have recent practical nursing experience to maintain their clinical credibility and competence [1]. The ensuing debates therefore focused on whether nurse teachers should engage in clinical practice as a way of maintaining their clinical credibility or not [3].

Literature reflects a dichotomy of views regarding the role of the nurse educator. Some are proponents of a more clinical orientation whereas others support an educationalist orientation. Webster et al. (2010) argue that clinical credibility of nurse teachers is essential if students are to become competent practitioners and this view is echoed by others [4]. This calls for nurse academicians to engage in clinical practice which will help them to keep up to date with current nursing practice so that what is taught in theory relates to what is carried out in practice [5] [6]. This would also help them to maintain clinical competence and confidence as well as to deliver clinically relevant teaching which is based on recent practice [7]. Moreover, Humphries et al. (2000) claim that nurse educators' involvement in clinical practice allows translation of theory to practice [8].

Acton, Gough and McCormack (1992) support the development of nurse educators as educationalists and that their role should be that of facilitating and supporting clinical learning [9]. Osborne indicates that the role of nurse teachers is complex so that in an attempt to fulfill all the roles, they will spread themselves thinly leading to poor quality of clinical learning experiences [10]. She suggests that nurse educators would be able to offer more constructive support by enhancing their educational skills in supporting ward staff so as to create a positive clinical learning environment. Osborne therefore recommends that nurse educators should stop trying to remain clinically up to date but should utilize and develop their educational skills in supporting ward staff and this is also echoed by others [11] [12]. Acton et al. (1992) contend that the continual presence of nurse educators within the clinical area could be considered as doubling up of roles and resources [9]. However, this might be the case where there is an effective mentoring system. In countries where there is severe nursing shortage, purely relying on mentors to facilitate clinical learning may not be practically feasible.

In Malawi nurses are trained in nursing schools and nursing education takes both clinical and an educationalist orientation. Clinical teaching is one of the core components of the role of the nurse educators. Most of the clinical teaching of nursing students is done by nurse educators. Less is known on the experiences of the students with the clinical teaching that they receive. This study was therefore set to explore the clinical learning experience of undergraduate nursing students in Malawi. This paper discusses the findings of the perceptions of Malawian student nurses on the role of the nurse educators. The findings are very relevant to all nursing institutions that use both clinical and an educationalist orientation. The findings provide an insight to nurse educators on how best they can position themselves in the clinical area so that they help student have meaningful clinical learning.

\section{Methodology}

\subsection{Research Design}

The study employed a qualitative research approach and this was chosen because it investigates the social world from the perspective of the people being studied [13]. The social world is the world interpreted and experienced by its members from the "inside" [14]. Student nurses are "insiders" in so far as clinical learning is concerned and their narrative accounts provide the "insider view." There are several approaches to a qualitative inquiry and in this study hermeneutic phenomenology was used to explore the clinical learning experience of undergraduate nursing students in Malawi. Sokolowski (2000) defines phenomenology as the study of human experience and the way phenomena manifest through such experience [15]. Clinical learning is a human experience and this justified the need for a phenomenological inquiry. There are two main approaches to a phenomenological inquiry namely, hermeneutic/interpretive and descriptive phenomenology. Husserl (1859-1938) developed descriptive phenomenology while Heidegger developed hermeneutic phenomenology. Bracketing was one of Husserl's major concepts, and this implies suspending prior knowledge so that fresh impressions about phenomena can develop without any interference on the interpretive process [16]. Fleming et al. (2003) argue that it is very difficult, if not impossible to lay aside one's preunderstanding or foreknowledge, which the current authors 
concur with, and it is for this reason that descriptive phenomenology was not used in this study [17]. Heidegger (1889-1976) and Gadamer (1900-2002) are the two phenomenologists whose philosophical tenets underpin the study.

\subsubsection{Application of Heidegger's Philosophical Tenets to the Study}

Heidegger is one of the existential phenomenologists and he believed that "humans" are always caught up in a world into which they find themselves thrown. This led him to develop the notion of "In-der-welt-sein", which means "being-in-the-world" [18]. According to Heidegger, phenomenology is directed at understanding "Dasein", which is translated as "the mode of being human" or the situated meaning of a human in the world [19]. This implies that our being is always a "being-in-the-world", and therefore our understanding of the world comes from our experiences in the world that we must make sense of [20]. Furthermore, Heidegger claimed that the goal of phenomenology must be to understand "Dasein" from within the perspective of a lived experience [18]. This reflects the need to understand the "life world" of student nurses on the basis of their lived experience, which constitutes substantially their clinical learning experience. Heidegger also believed that phenomena manifest themselves in a "self-concealing manner" [18], implying that phenomena do not manifest themselves fully. His assumption was that the lived experience is veiled and the researcher's responsibility is to unveil the experience through interviewing, reading and writing [21]. He believed that phenomena cannot simply be described, but rather that phenomenology has to do with the seeking of hidden meanings which can be achieved through interpretation of text. However, in this paper, the presented findings have not been interpreted. The findings have been presented according to what the students described as they narrated their experience.

\subsubsection{Application of Gadamer's Philosophical Tenets to the Study}

Gadamer (1900-2002) is acknowledged as being central to the development of contemporary hermeneutic philosophy [22]. His main concern was what made understanding possible [17]. He believed that Language is the universal medium in which understanding occurs and he wrote, "Human language must be thought of as a special and unique life process since, in linguistic communication, 'world' is disclosed" [23]. Similarly, Holstein and Gubrium (1997) maintain that meaning is actively and communicatively assembled in the interview encounter [24]. In view of this, conversational interviews were conducted to obtain accounts of students' experience.

Additionally, Gadamer believed that understanding can only be possible in the presence of a historical awareness which he referred to as prejudice or preunderstanding. The concept of prejudice does not carry with it any negative connotations but it is a judgment which is rendered before all the elements that determine a situation have been finally examined [23]. Debesay et al. (2008) assert that our prejudices or preunderstanding are necessary conditions for our understanding of the present [25]. Furthermore, Gadamer believed that understanding is always an historical, dialectic and linguistic event and is achieved through what he called "fusion of horizons". The concept of horizon refers to "the range of vision that includes everything that can be seen from a particular vantage point" [23]. Understanding involves a critical and reflective process which enables the researcher to create more empowering interpretations [20].

\subsection{Study Setting and Access to Participants}

The study took place at a University nursing college in Malawi and the participants were recruited by the first author. Third and fourth year undergraduate nursing students were purposively selected to participate in the study. This sampling method selects individuals for study participation based on their particular knowledge of a phenomenon, for the purpose of sharing that knowledge [26] and this was the main reason for selecting senior students as the study population. The sample consisted of 30 participants who were recruited through volunteering, meaning that they voluntarily agreed to participate in the study from among the purposively selected study population. The sample was large because in a hermeneutic phenomenological study, $10-25$ participants are usually an acceptable sample size [27]. However, a larger sample was obtained in order to attain data saturation.

\subsection{Ethical Considerations}

Ethical approval for the study was obtained from the ethics committee at the School of Heath in Social Science (University of Edinburgh) and locally in Malawi, from the College of Medicine Research and Ethics Committee 
(COMREC) of the University of Malawi, and the reference number is P.09/09/828. In addition, permission to conduct the study was sought from the head of the institution where the study took place and verbal and written consent were obtained from individual participants.

\subsection{Data Collection}

Data was collected by the first author and this involved conducting interviews with the study participants in order to obtain narrative accounts of their clinical learning experience. The interviews were conversational in nature, implying that they were conducted in such a way as to initiate a dialogue and not a question and answer response. This is consistent with Gadamer who believed that language has its true being only in dialogue where human understanding is concerned [23]. According to Gadamer, the aim of the conversation is to allow immersion into the subject matter and this enables the researcher to gain understanding of the phenomena being investigated [17]. Each participant had one interview session, which lasted one hour on average, and was recorded on an audio tape recorder and transcribed verbatim.

\subsection{Data Analysis}

Data analysis was guided by a framework which was developed through modification of Colaizzi's (1978) procedural steps for phenomenological analysis [28]. The modification was essential because of some observed limitations. Colaizzi's approach does not portray the important role that reflection plays in enabling the researcher to develop meaning of the phenomena being investigated. The method mainly involves extracting phrases or sentences that directly pertain to the investigated phenomena. However, phenomenological analysis goes beyond mere extraction of phrases, the researcher deeply engages with texts through reflection and gains insight of the phenomena being investigated [29]. Additionally, Colaizz's method does not suggest that all understanding is dependent upon preunderstanding [17], which Gadamer greatly upholds as being significant. Recognizing that Gadamer's philosophical tenets underpin this study; this was considered a major weakness of Colaizzi's method. The modification involved incorporation of some ideas from Diekelmann (1992) and Fleming et al. (2003) [17] [30]. These informed the additional steps which were included, creating an eclectic framework which guided the phenomenological analysis.

Data analysis progressed following step by step approach. The interviews were followed by verbatim transcriptions. The next step involved reading and examining each interview text to identify expressions which reflect the fundamental meaning of the text as a whole. Line by line reading was done to extract phrases or sentences that directly pertain to the clinical learning experience and to identify salient issues emerging from the narrative accounts. This was a rigorous and reflective process of going over every word, phrase, sentence and paragraph in the text to elicit the participants' meanings [31]. This enabled the identification of emerging themes.

\section{Findings}

The study findings reveal undergraduate students' perceptions on the role of the nurse educator during clinical placements. They reveal that educators should take a leading role in the facilitation of clinical learning. The findings have been presented under the following themes; nurse educators' role failure in supporting students during clinical placements, student's perspectives of the ideal role of nurse educators during clinical placements, and approaches of clinical supervision.

Nurse educators' role failure in supporting students during clinical placements

The study reveals that there is minimal supervision by nurse educators. Their visits to the clinical area are quite infrequent. The following excerpt eloquently captures concerns which were expressed by most of the students.

Supervision by our educators is not all that good... Sometimes you would stay may be two weeks without a supervisor (educator) coming; when you ask you are told that she went for a seminar or she is somewhere... if she comes, maybe she will come only in the morning, and she has two wards to supervise.

As a consequence of the infrequent visits to the clinical area, educator/student relationships are not established and the following excerpt illustrates this. 
Sometimes you would be in an allocation may be for six weeks and not have that relationship with your supervisor (educator). Maybe you could actually ask yourself I don't think this supervisor even knows my name. Because maybe she will just come then meet you in a group and discuss something but not having that personal like a lecturer and a student, like one to one whereby maybe you have other problems that you cannot talk about them in a group... But when you have that relationship I feel it's good. And in our supervision that was not much common.

Additionally, the observed role failure hinders students from becoming acquainted with the educators, such that their presence makes them to feel stressed. One of the students had this to say:

And most of the clinical allocations we don't have much supervision. The educators come maybe once a week and maybe once in two weeks. So when they come, instead of maybe supervising, it's like they are a threat or a stress to the students

The study findings indicate the need for better educator/student relationships which accommodate both personal and academic components of the student's life. One of the students described it this way:

I had a lecturer who would always look at my strengths and my weaknesses and assisted me to work on my weaknesses. the whole interaction was so holistic in terms that she did not only look at my academic aspect but she was also looking at the personal aspect, which in most cases sometimes most educators maybe take not into account; they only look at the academic aspect.

Such relationships are necessary because sometimes students encounter personal problems which affect them emotionally and they need support from educators. One of the students described it this way:

Sometimes you may have some problems maybe at home or some other issues. Sometimes you may become disturbed, you may not concentrate, and you may not work hard. And you become confused and you don't know what to do and who to talk to and in most cases such issues it's difficult to just stand up and start talking about them, because some of them sometimes are sensitive issues and they need someone maybe to listen to your story.

These findings reveal role failure among nurse educators which is mainly evidenced by intermittent visits to the clinical area. This affects the development of student-teacher relationships such that students feel stressed by the presence of the educator in the clinical setting.

The students' perspectives of the ideal role of educators' during clinical placements

The study largely portrays role failure among educators in fulfilling their clinical teaching responsibilities. However, students' narratives indicate that presence of the educator in the clinical setting is essential in helping them to learn. Despite the educators' role failure, the findings illustrate that there are some positive teaching and learning encounters. One of the students made the following comments:

When the lecturers come, you feel confident. They encourage you; they tell you you've done this very well that is good. You've done this wrongly, next time I want to see how we can go about it.

The study reflects the students' perceptions of the ideal role of educators during clinical placements. One of the students had this to say:

But in most cases they say (educators) I would like to see your patients. Which patients have you taken care of this morning? Where are they...But in the first place, I feel they are supposed to be there first of all, knowing the patients themselves, and saying this patient, let me take care of her or him then learn from me on what I am doing... Because in their absence we usually adopt what the clinical nurses or the qualified nurses usually do.

Likewise, another student stated:

The other problem I have found... most of the educators here go into the wards but they don't do what they teach the students. They will just stand and say what are you doing? No do this like this, do that like that. I don't like that, I would rather be alone than somebody standing on my back and saying do this and do that. Because I assume they are supposed to demonstrate. We are supposed to work hand in hand.

Additionally, another student said: 
Most of the times they will just come (educators)... You haven't done it correctly; next time ah do it like this, like this. It's like the same theory that we had in class, but in the hospital, I feel the supervisor has to do hands-on (demonstrate) so that we can see. Because if you have failed to do the wound dressing while you learnt in class that means there is something that is missing that at least if you visualize then you will remember.

From the above excerpts, it is evident that Malawian nursing students prefer that educators should take a leading role in teaching students during clinical placements. The study also reveals that as educators work together with students, they will be in a position to identify the students' strengths and weaknesses and be in a better position to help them to improve. The following extract confirms this.

When the supervisor (educator) comes to the ward and we work together...I can say the supervisor will have enough time to observe you, to know your weaknesses and strengths...they will know how to help you to improve.

The study findings clearly portray the reasons why Malawian nursing students prefer that educators should take a leading role in teaching them during clinical placements. There is dissatisfaction with the teaching which is conducted by some of the clinical nurses. One of the students had this to say:

Due to shortage of staff and may be due to shortage in the number of registered nurses, the type of learning that we get from these enrolled nurses leaves a lot to be desired because they are these nurses who do most of the short cuts.

Another student said:

A lot of us we learn the things from other nurses, most of them don't do the procedures rightly as they are written in the books. But when an educator can come and you observe, really we learn the real way of doing procedures. But because they don't usually come, we have deficiencies in doing some of these procedures.

Furthermore, another student said:

You just learn maybe through other nursing officers who for sure because of the many patients most of the procedures are done non-procedurally.

On the other hand, the study also reveals that there are also some other nurses who feel that they cannot be able to teach a student who is pursuing a Bachelors degree because they possess a lower qualification. The following excerpt illustrates this:

In some places where I found it difficult to learn they were saying, I am a student pursuing a Bachelor's degree in nursing, and the nurses were saying I am a holder of a certificate, I don't think I can teach you...If you have problems, maybe you can consult someone else who can assist you.

These findings reveal the students' perspectives on the ideal role of nurse educators during clinical placements. Malawian nursing students prefer to be taught by educators as they provide patient care and the reasons for such a preference are also clearly stated.

\section{Approaches of clinical supervision}

The study reveals various approaches which educators utilize during clinical placements as they interact with students. The findings indicate that the approach determines whether learning will be facilitated or not. One of the students had this to say:

I consider an educator when you are in the ward not to be like a watch dog... When an educator is just pointing out areas where you haven't done right, is just saying... up to this time you are in this year but you can't even do this...it discourages a learner. But when they are encouraging you to say you know what, I have been observing you; I can see that you are able to do this...I have also noticed that you've got these areas of weaknesses which need improvement and if you can do this...you are going to make a good nurse. That encourages a student... So the approach itself is what can make you to say ah do I go on?

The study findings also reflect some negative approaches to clinical supervision which some of the educators 
employ as they interact with students during clinical placements. Students mentioned that some educators police them and the following excerpt illustrates this.

Sometimes the other clinical supervisors may make learning so hard in a sense that, for example, you are doing a procedure on a client. The clinical supervisor would come in the sense like policing you. So you are definitely scared, you cannot perform that procedure as it is expected just because you are anxious...The policing is being done in the sense that you are doing the procedure and the supervisor comes in, starts asking you questions.

Similarly, another student said:

I think supervising is not policing us. I believe that if you are there just to intimidate or just to question a student I think it will not be good but we should work hand in hand, we should work as a team.

Additionally, some educators shout at students or correct them at the patient's bedside, which students do not like because it makes them to feel humiliated. One of the students expressed the following sentiments:

But there are some educators who when they come to the clinical area, they would shout at you while you are at the patient's bed side and say, "we don't do like that! You want to harm the client!" So when clients hear that, they don't trust you anymore...Y You feel humiliated and you don't like working anymore...So those educators discouraged me who shouted at me whilst doing a procedure.

Similarly another student said:

Some supervisors will actually talk to you at that patient's bedside with the patient there listening and the patient will know that this student didn't do the right thing.... And the next time you come they don't have that trust in you and even you, you are demotivated...you don't learn because you have those negative feelings; and when that supervisor comes again you will not want to go and interact with that person.

Although students may be wrong and sometimes it could be that what they are doing could be harmful to the patient, the study reveals that students still prefer to be corrected amicably and not to be shouted at. One of the students said:

There are times whereby what the student is doing can do harm to the patient. So I prefer to say when the supervisor sees that... the supervisor should tell the student to relax while she takes over, she continues what the student was doing and she finishes and after finishing the procedure go aside and you discuss rather than just, you made a mistake! You would have killed the patient! This is not how you do it! That person feels bad, it brings shame and embarrassment and mistrust in the patient that this one would have killed me.

The study depicts the students' perceptions on attributes which educators should exhibit in order to effectively facilitate learning during clinical placements. One of the students had this to say:

When an individual is having a smiling face or a welcoming face that person is likeable by a lot of people, so it's the same with the supervisors. Let's say they've found you at the ward and they are coming with a gloomy face you start fearing...but if she comes and she smiles at you, she greets you then you tend to relax, you do things calmly...because that supervisor is so welcoming... She greets you with a nice face, calmly, she asks you what you have done...gives an encouragement on what you have done and she continues on telling you the shortfalls, that supervisor encourages a lot.

Similarly, another student said:

we are youth so they should be youth friendly not coming there like some come, as if they are already angry with something else...you just run away...But some educators come while smiling; even greeting you but some educators they don't even greet you (laughter). So they should also be smiling at us, and they should be youth friendly yah.

These findings reveal both positive and negative approaches of clinical supervision which nursing faculty employ. Students prefer approaches which do not demean their self-worth and an educator who smiles at students makes a difference. 


\section{Discussion}

The study reveals that educators spend less time in the clinical setting with students and they are not able to support them adequately, which reflects role failure. Generally the findings clearly indicate that nursing students desire to have more contact with educators. The educators' sporadic clinical visits hinder the development of educator-student relationships. In one of the excerpts a student mentions of wondering whether the educator knew her personally by name. Nylund and Lindholm (1999) also reflect similar findings in that the students who participated in their study expressed a wish to be treated as individuals by the supervisor remembering their names [32]. Gillespie (2002) conducted a qualitative study which was undertaken to explore and describe undergraduate nursing students' experiences of connection within the student-teacher relationship in clinical nursing education [33]. The study findings revealed that student nurses experienced either connected or non-connected student-teacher relationships. Furthermore, the study revealed that student-teacher connection has a positive influence on clinical learning experiences. Gillespie (2005) views student-teacher connection as a place of possibility in that it enables transformation and growth for both the teacher and the student [34].

Additionally, this current study illustrates that the educator-student relationship should be holistic, accommodating both personal and academic aspects of the student's life. This is essential because sometimes students encounter personal problems and they need educators who can listen to them and support them emotionally. These findings are also consistent with Gillespie (2002) who asserts that connected relationships focus on personal and professional components, whereas in non-connected relationships, the focus is only on work and there is no acknowledgement of personal aspects. As the study reveals, the support rendered to students experiencing problems goes a long way in averting fatal consequences such as failure. These findings lend support to the assertion that that student-teacher connection supports teachers and students in various challenging situations such as working with students at risk of failing [34].

A resounding message from the Malawian nursing students is that nurse educators should teach them during clinical placements through provision of direct patient care. This portrays an educational model which is 8 different from what is commonly reflected in literature. The mentor is commonly portrayed as being central to the facilitation of clinical learning, whereas the educator assumes a liaison role [35]. This current study reveals that as nurse educators engage in direct patient care students become motivated to learn and they really attach great significance to such clinical learning encounters. In the absence of such teaching moments students simply adopt what clinical nurses do, whether it is good practice or not. However, Elliot and Wall (2008) indicate that the existence of nurse education within tertiary education means that nurse educators are academics who besides their classroom/clinical teaching responsibility are also expected to engage in scholarly activities such as research and publication [6]. This hinders the academics from having contact with the clinical environment and maintaining clinical credibility and competence [6].

The students' view that educators should teach them through direct patient care lends support to the assertion by Webster (1990), who contends that the teaching of clinical skills is an inherent responsibility of nurse teachers [36]. Contrary to the findings of this current study, previous research reflects that nurse educators involvement in clinical teaching through direct patient care is disruptive, unrealistic and frustrating [37] [38]. Carlisle et al. (1997) investigated the clinical role of the nurse teacher within the project 2000 framework and the study participants perceived it not to be probable that nurse teachers would work with students in providing direct patient care [39]. This was perceived to be a probable role for clinical nursing staff. Forrest et al. (1996) also reflect students' views of the clinical role of the nurse teacher whereby the students valued the "support role" rather than the "teacher role" and the latter was perceived to be a role of clinical nursing staff [37].

Two issues emerging from this study explain why Malawian nursing students prefer that educators should teach them as opposed to clinical nurses. Primarily, students expressed concerns over the academic credibility of some clinical nurses because the majority of the practicing nurses are nurse technicians/enrolled nurses. At the same time, some of these nurses tend to doubt their own ability to teach undergraduate student nurses and they decline to do so. Wilson-Barnett et al. (1995) reflect similar findings in that some of the nurses who participated in their study had negative opinions towards supporting students during clinical placement because they lacked appreciation of what they could offer [40]. Hegarty et al. (2008) indicate that undergraduate programmes should enable student nurses to develop skills in analysis, critical thinking, problem solving and reflective practice [41]. Nurse technicians/enrolled nurses might not possess such skills and whereas they do teach nursing students, we argue that this compromises the quality of their learning. The other reason is the dissatisfaction which nursing 
students expressed regarding the way some of the qualified nurses teach them. Students expressed dissatisfaction with the way the nurses perform procedures, alleging that most nurses do "shortcuts". This affects students' skill acquisition in a sense that they also learn the "shortcuts".

The study portrays two possible approaches in which educators interact with students during clinical placements. There are educators who are approachable and friendly and such educators motivate students to learn. On the other hand, there are educators who seem to be policing students. This occurs when an educator finds a student performing a procedure and begins to "fire" questions without allowing the student to finish the procedure. The student becomes scared and anxious and cannot perform the procedure as is required. This hinders learning and these findings are consistent with Oermann and Lukomski (2001) who revealed the clinical instructor as the primary factor that hindered students' learning [42]. Such faculty behavior intimidates students and makes them to be overly stressed.

Such student-teacher interactions occur as a result of what Gillespie (2002) calls "non-connected" relationships. She claims that such teachers have a tendency to "grill" students with questions, offer only negative feedback, constantly critique and "watch them like a hawk" [33] and the students who participated in this current study expressed similar concerns. The policing approach indicates that some educators interact with students in an autocratic manner and Griffith and Bakanauskas (1983) assert that such approaches to nursing education produce a sense of powerlessness in the students which negatively impacts on the learning process [43]. Students reported of shame and humiliation which occurs as a result of educators shouting at them or correcting them in an embarrassing manner in the presence of patients. This is consistent with Bond (2009) who supports that shaming practices do occur in nursing education and that they seriously impede effective teaching and learning [44].

The approach to clinical supervision significantly determines the success of the student-educator interaction in the clinical setting. These findings illustrate the importance of the educator's calm disposition and effective communication skills and Kelly (2007) reflects similar findings [45]. The educator's attributes are vital in facilitating clinical learning and Lopez (2003) supports this indicating that teachers' behaviors in clinical areas play an important part in the learning process [46]. The educator should have a welcoming and smiling face and should greet students as this makes them to relax and to perform procedures calmly. Levette-Jones et al. (2007) reveal that welcoming, accepting and supportive clinical educators increase student capacity and motivation for Learning [47]. Showing personal interest in students appears to be one of the essential clinical teaching behaviors. The educator should be available to students, being with them in the clinical area so as to know their progress. The educator should be friendly and approachable. This is important because it makes the students feel free to ask questions. The educator should be flexible and understanding, knowing that $\mathrm{s} / \mathrm{he}$ is dealing with students who can make mistakes and need to be corrected amicably. Where a student is doing well there should be room for commendation as this motivates the student.

\section{Recommendations}

The study raises pertinent issues regarding the role of the nurse educator in facilitating clinical learning. It reveals that nurse educators have a potential to facilitate students' learning but at the same time they can also hinder students' learning. The question worthy asking is "how can we meet students in a manner that ensures the fruitfulness of teaching-learning interactions" [34]. To this end, the following recommendations are proposed:

There is evidence that nurse educators have a potential to effectively facilitate student learning in the clinical setting. Contrary to existing literature, this current study illustrates that nurse educators should assume the teacher role in addition to the supportive role. It is therefore recommend that in Malawi and other countries with a similar educational system, nurse educators should aim at maintaining both clinical credibility and competence and also to promote their personal development as educationalists. It is argued that if nurse educators engage in clinical teaching on a regular basis they would be in a position to maintain their clinical credibility.

Clinical teaching should be a shared responsibility for both nurse educators and clinical nurses, but the former should assume a leading role. To do this, there is need for clear agreeable policies between the teaching institutions and the hospitals on student clinical teaching so that every nurse responsible should talk part in teaching the students.

Nurse educators should also support clinical staff through their educational expertise to enhance their clinical teaching abilities. Nurse educators should be connected to the teaching hospitals and offer evidence based prac- 
tice guidelines that should support practice. In addition nurse educators should orient clinical staff on clinical teaching and on how best they can support students. This is essential in view of the concerns nursing students expressed regarding the way clinical nurses teach them. It is argued that, if this is done, a conducive learning environment for students, clinical nurses and nurse educators would be created.

The "policing" which some of the students alluded to denotes the possibility of non-connected relationships. Student-teacher connection develops when faculty members espouse a caring educational philosophy. We therefore recommend that this is an educational philosophy which every nurse educator should embrace in order to inculcate a caring attitude in nursing students. Diekelmann (1990) asserts that a common commitment of nurses is to care, whether we provide nursing care, teach students and conduct research, we must conduct our practice in caring ways [48]. In support of this notion, Beck (2001) asserts that caring must become a way of being for both faculty and students [49]. However, there is need for further studies to investigate what Malawian nursing students would perceive as caring faculty behavior. Beck (1991) indicates that when nursing faculty knows the behaviors students view as caring, they can incorporate these into their day to day interactions with students [50].

The study reveals some shaming practices during student-teacher interaction in the clinical setting. Students are sometimes shouted at and humiliated and Nylund and Lindholm (1999) revealed in a study that such studentteacher interactions make students to feel hurt [30]. In view of this, Nylund and Lindholm (1999) suggest that clinical supervision should be based on the same premises as caring ethics [32]. They cite Eriksson (1995) who defines caring ethics as the basic attitude we take towards a human being and the caring process. It is therefore recommend that as nurse educators interact with students in the clinical setting, they should endeavor to respect the students' dignity.

The study reveals that nursing students' experiences vary; others have good experiences whereas others have bad experiences. This is mainly dependent on the behavior of the responsible faculty member and Lopez (2003) maintains that teachers' behaviors in clinical areas play an important part in the learning process [46]. To this end, Tanner (1999) indicates that great teaching has little to do with the technique of teaching, but it has to do with the teacher as a person. It is recommended that educators should be having frequent workshops on effective and innovative clinical teaching and supervision in order to effect a change in the behavior of some nurse educators [51]. It is also essential that nurse educators should demonstrate passion for their work as this promotes fruitful teaching learning encounters [51].

\section{Conclusion}

The study illustrates that there is inadequate student support during clinical placements by educators. Their visits to the clinical setting are quite intermittent and brief which hinders development of educator-student relationships. Consequently, the educators' presence in the ward is perceived by the students as a threat and it induces stress among students. This confirms that the student-educator relationships are central to the promotion and facilitation of clinical learning. Some educators tend to be impersonal in their approaches to clinical supervision and they employ what students interpret as "policing", or they shout at students or correct them in an embarrassing manner in the presence of patients. Students resent such educators and they avoid them when they visit the clinical area. Despite the educators' role failure, students' narratives indicate that they have a great potential in facilitating clinical learning.

\section{References}

[1] Barret, D. (2007) The Clinical Role of Nurse Lecturers: Past, Present, and Future. Nurse Education Today, 27, $367-374$. http://dx.doi.org/10.1016/j.nedt.2006.05.018

[2] Mallik. M. and Aylott, E. (2005) Facilitating Practice Learning in Pre-Registration Nursing Programmes-A Comparative Review of The Bournemouth Collaborative Model and Australian Models. Nurse Education in Practice, 5, 152-160. http://dx.doi.org/10.1016/j.nepr.2004.08.001

[3] Fisher, M.T. (2005) Exploring How Nurse Lecturers Maintain Clinical Credibility. Nurse Education in Practice, 5, 21 29. http://dx.doi.org/10.1016/j.nepr.2004.02.003

[4] Webster, S., Lopez, V., Allnut, J., Clague, L., Jones, D. and Bennett, P. (2010) Undergraduate Nursing Students' Experiences in a Rural Clinical Placement. Australian Journal of Rural Health, 18, 194-198. http://dx.doi.org/10.1111/j.1440-1584.2010.01153.x 
[5] Cave, I. (2005) Nurse Teachers in Higher Education-Without Clinical Competence, Do They Have a Future? Nurse Education Today, 25, 646-651. http://dx.doi.org/10.1016/j.nedt.2005.09.004

[6] Elliot, M. and Wall, N. (2008) Should Nurse Academics Engage in Clinical Practice? Nurse Education Today, 28, 580587. http://dx.doi.org/10.1016/j.nedt.2007.09.015

[7] Bently, J. and Pegram, A. (2003) Achieving Confidence and Competence for Lecturers in a Practice Context. Nurse Education in Practice, 3, 171-178. http://dx.doi.org/10.1016/S1471-5953(02)00112-9

[8] Humphreys, A., Gidman, J. and Andrews, M. (2000) The Nature and Purpose of the Role of the Nurse Lecturer in Practice Settings. Nurse Education Today, 20, 311-317. http://dx.doi.org/10.1054/nedt.1999.0453

[9] Acton, L., Gough, P. and McCormack, B. (1992) The Clinical Nurse Tutor Debate. Nursing Times, 88, 38-41.

[10] Osborne, P. (1991) Nurse Teacher and Ward Based Learning. Senior Nurses, 11, 28-29.

[11] Meskell, P., Murphy, K. and Shaw, D. (2009) The Clinical Role of Lecturers in Ireland: Perceptions from Key Stake-Holder Groups in Nurse Education on the Role. Nurse Education Today, 29, 784-790. http://dx.doi.org/10.1016/j.nedt.2009.03.014

[12] McSharry, E., McGloin, H., Frizzell, A.M. and Winters-O’Donnell, L. (2010) The Role of the Nurse Lecturer in Clinical Practice in the Republic of Ireland. Nurse Education in Practice, 10, 189-195. http://dx.doi.org/10.1016/j.nepr.2009.08.004

[13] Bryman, A. (2004) Social Research Methods. Oxford University Press, Oxford.

[14] Blaikie, N. (2000) Designing Social Research: The Logic of Anticipation. Polity Press, Cambridge.

[15] Sokolowski, R. (2000) Introduction to Phenomenology. Cambridge University Press, Cambridge.

[16] LeVasseur, J.J. (2003) The Problem of Bracketing in Phenomenology. Qualitative Health Research, 13, 408-420. http://dx.doi.org/10.1177/1049732302250337

[17] Fleming, V., Gaidys, U. and Robb, Y. (2003) Hermeneutic Research in Nursing: Developing a Gadamerian-Based Research Method. Nursing Inquiry, 10, 113-120. http://dx.doi.org/10.1046/j.1440-1800.2003.00163.x

[18] Moran, D. (2000) Introduction to Phenomenology. Routledge, London.

[19] Laverty, S.M. (2003) Hermeneutic Phenomenology and Phenomenology: A Comparison of Historical and Methodological Considerations. International Journal of Qualitative Methods, 2, 21-35.

[20] Freeman, M. (2007) Performing the Event of Understanding in Hermeneutic Conversations with Narrative Texts. Qualitative Inquiry, 13, 925-944. http://dx.doi.org/10.1177/1077800407304463

[21] Wilson, H.S. and Hutchinson, S.A. (1991) Triangulation of Qualitative Methods: Heideggerian Hermeneutics and Grounded Theory. Qualitative Health Research, 1, 263-276. http://dx.doi.org/10.1177/104973239100100206

[22] Pascoe, E. (1996) The Value of Nursing Research of Gadamer's Hermeneutic Philosophy. Journal of Advanced Nursing, 24, 1309-1314. http://dx.doi.org/10.1111/j.1365-2648.1996.tb01039.x

[23] Gadamer, H.G. (2004) Truth and Method Translation. Revised by Weinsheimer, J. and Marshall, D.G., Continuum, London.

[24] Holstein, J.A. and Gubrium, J.F. (1997) Active Interviewing. In: Silverman, D., Ed., Qualitative Research: Theory, Method and Practice, Sage, London, 113-129.

[25] Debesay, J., Naden, D. and Slettebo, A. (2008) How We Do We Close the Hermeneutic Circle? A Gadamerian Approach to Justification in Interpretation in Qualitative Studies. Nursing Inquiry, 15, 57-66. http://dx.doi.org/10.1111/j.1440-1800.2008.00390.x

[26] Streubert, H.J. and Carpenter, D.R. (2011) Qualitative Research in Nursing: Advancing the Humanistic Imperative. Wolters Kluwer, Philadelphia.

[27] Burns, N. and Grove, S.K. (2009) The Practice of Nursing Research: Conduct, Critique and Utilization. WB Saunders Company, London.

[28] Colaizzi, P.F. (1978) Psychological Research as the Phenomenologist Views It. In: Valle, R.S. and King, M., Eds., Existential Phenomenological Alternatives for Psychology, Plenum, New York, 48-71.

[29] Richards, L. and Morse, J.M. (2007) Readme First for a User's Guide to Qualitative Methods. Sage Publications, Thousand Oaks, 11.

[30] Diekelmann, N.L. (1992) Learning as Testing: A Heideggerian Hermeneutical Analysis of the Lived Experiences of Students and Teachers in Nursing. Advances in Nursing Science, 14, 72-83. http://dx.doi.org/10.1097/00012272-199203000-00010

[31] Hycner, R.H. (1985) Some Guidelines for the Phenomenological Analysis of Interview Data. Human Studies, 8, 279303. http://dx.doi.org/10.1007/BF00142995 
[32] Nylund, L. and Lindholm, L. (1999) The Importance of Ethics in the Clinical Supervision of Nursing Students. Nursing Ethics, 6, 278-286. http://dx.doi.org/10.1177/096973309900600403

[33] Gillespie, M. (2002) Student-Teacher Connection in Clinical Nursing Education. Journal of Advanced Nursing, 37, 566-576. http://dx.doi.org/10.1046/j.1365-2648.2002.02131.x

[34] Gillespie, M. (2005) Student-Teacher Connection: A Place of Possibility. Journal of Advanced Nursing, 52, $211-219$. http://dx.doi.org/10.1111/j.1365-2648.2005.03581.x

[35] Brown, L., Herd, K., Humphries, G. and Paton, M. (2005) The Role of the Lecturer in Practice Placements: What Do Students Think? Nurse Education in Practice, 5, 84-90. http://dx.doi.org/10.1016/j.nepr.2004.03.006

[36] Webster, R. (1990) The Role of the Nurse Teacher. Senior Nurse, 10, 16-18.

[37] Forrest, S., Brown, N. and Pollock, L. (1996) The Clinical Role of the Nurse Teacher: An Exploratory Study of the Nurse Teacher's Present and Ideal Role in the Clinical Area. Journal of Advanced Nursing, 24, 1257-1264. http://dx.doi.org/10.1111/j.1365-2648.1996.tb01033.x

[38] Corlett, J. (2000) The Perceptions of Nurse Teachers, Student Nurses and Preceptors of the Theory-Practice Gap in Nurse Education. Nurse Education Today, 20, 499-505. http://dx.doi.org/10.1054/nedt.1999.0414

[39] Carlisle, C., Kirk, S. and Luker, K.A. (1997) The Clinical Role of the Nurse Teachers within Project 2000 Course Framework. Journal of Advanced Nursing, 25, 386-395. http://dx.doi.org/10.1046/j.1365-2648.1997.1997025386.x

[40] Wilson-Barnett, J., Butterworth, T., White, E., Twinn, S., Davies, S. and Riley, L. (1995) Clinical Support and Project 2000 Nursing Student: Factors Influencing this Process. Journal of Advanced Nursing, 21, 1152-1158. http://dx.doi.org/10.1046/j.1365-2648.1995.21061152.x

[41] Hegarty, J., McCarthy, G., O’Sullivan, D. and Lehane, B. (2008) A Review of Nursing and Midwifery Education Research in the Republic of Ireland. Nurse Education Today, 28, 720-736. http://dx.doi.org/10.1016/j.nedt.2007.11.007

[42] Oermann, M.H. and Lukomski, A.P. (2001) Experiences of Students in Pediatric Nursing Clinical Courses. Journal of Specialists in Pediatric Nursing, 6, 65-72. http://dx.doi.org/10.1111/j.1744-6155.2001.tb00123.x

[43] Griffith, J. and Bakanauskas, A. (1983) Student Instructor Relationship in Nursing Education. Journal of Nursing Education, 22, 104-107.

[44] Bond, M.E. (2009) Exposing Shame and Its Effects on Clinical Nursing Education. Journal of Nursing Education, 48, 132-140. http://dx.doi.org/10.3928/01484834-20090301-02

[45] Kelly, C. (2007) Student's Perceptions of Effective Clinical Teaching Revisited. Nurse Education Today, 27, 885-892.

[46] Lopez, V. (2003) Clinical Teachers as Caring Mothers from the Perspectives of Jordanian Nursing Students. International Journal of Nursing Studies, 40, 51-60. http://dx.doi.org/10.1016/S0020-7489(02)00032-9

[47] Levette-Jones, T., Lathlean, J., Higgins, I. and McMillan, M. (2009) Staff-Student Relationships and Their Impact on Nursing Students' Belongingness and Learning. Journal of Advanced Nursing, 65, 316-324.

[48] Diekelmann, N.L. (1990) Nursing Education: Caring, Dialogue, and Practice. Journal of Nursing Education, 29, 300305.

[49] Beck, C.T. (2001) Caring within Nursing Education: A Metasynthesis. Journal of Nursing Education, 40, 101-109.

[50] Beck, C.T. (1991) How Students Perceive Faculty Caring: A Phenomenological Study. Nurse Educator, 16, 18-22. http://dx.doi.org/10.1097/00006223-199109000-00015

[51] Tanner, C. (1999) Teaching: Beyond Technique. Journal of Nursing Education, 38, 339. 
Scientific Research Publishing (SCIRP) is one of the largest Open Access journal publishers. It is currently publishing more than 200 open access, online, peer-reviewed journals covering a wide range of academic disciplines. SCIRP serves the worldwide academic communities and contributes to the progress and application of science with its publication.

Other selected journals from SCIRP are listed as below. Submit your manuscript to us via either submit@scirp.org or Online Submission Portal.
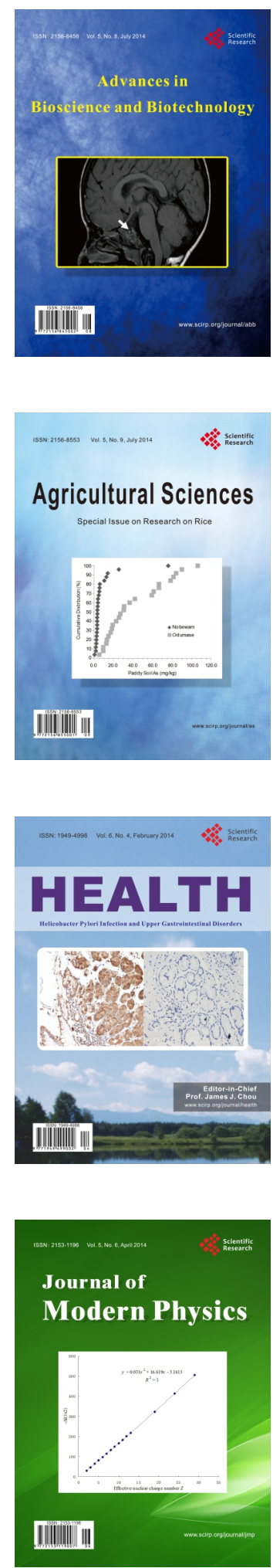
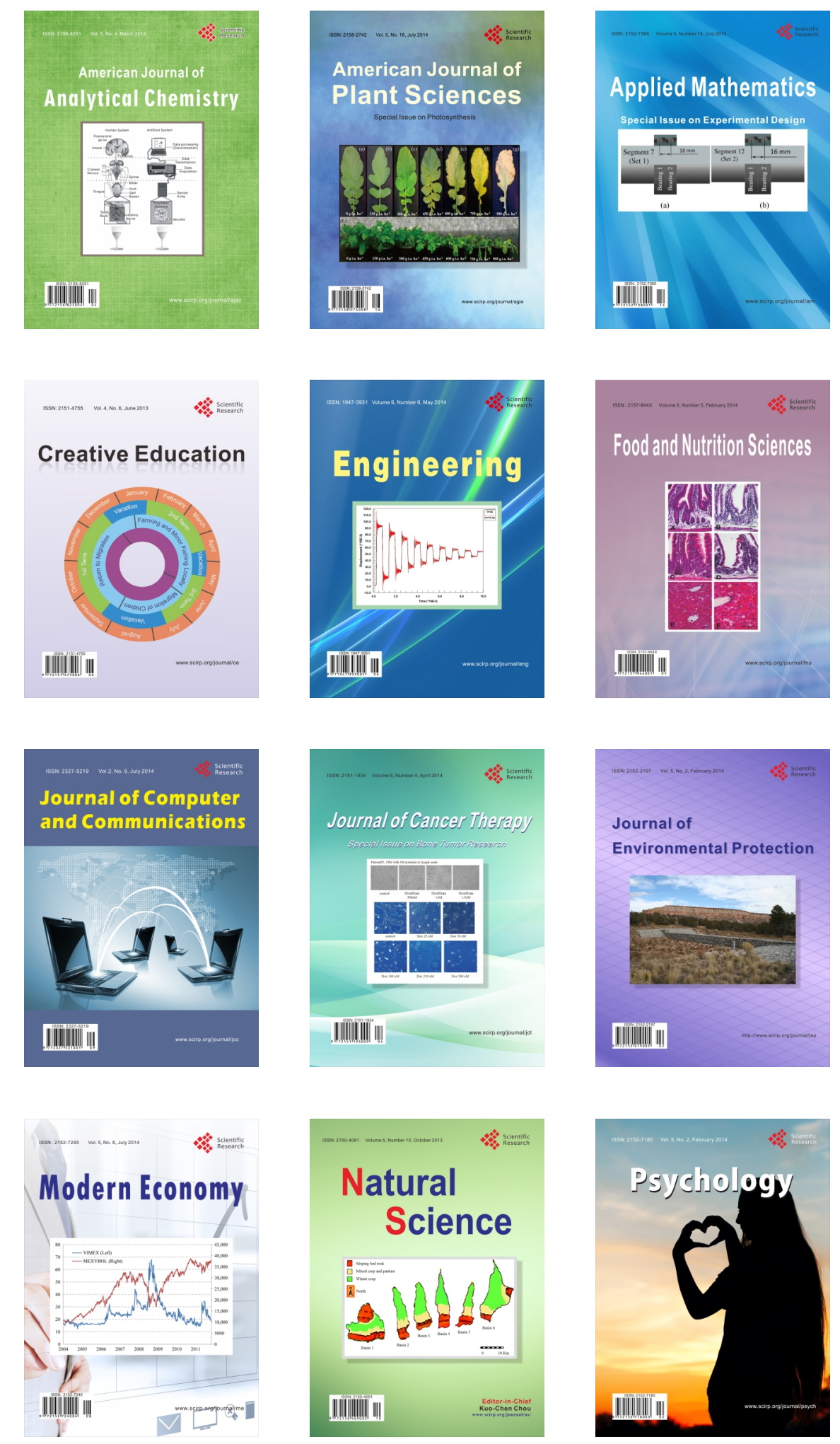